The Version of Record of this manuscript has been published and is available in Medical Reference Services Quarterly, August 10, 2020, DOI: 10.1080/02763869.2020.1778336.

\author{
INFORMATICS EDUCATION
}

Catherine Pepper, Column Editor

\title{
Thinking and Reading like a Scientist: \\ Librarians as Facilitators of Primary Literature Literacy
}

\begin{abstract}
Alexander J. Carroll
Abstract: Students entering graduate degree programs in science, technology, engineering, and math (STEM) fields or professional degree programs in the health sciences are expected to have adequate academic preparation in science process skills like the ability to read primary literature effectively. This column scrutinizes this assumption by examining how science is taught to undergraduates, finding that undergraduate STEM curricula rarely prepare students with the mastery of science process skills needed to succeed in graduate school. The column discusses some possible causes of this skill gap and suggests that academic and medical librarians are wellequipped to help students develop primary literature literacy skills. The column closes with a list of practical active reading strategies that librarians can share and model for students.
\end{abstract}

Keywords: science process skills, information literacy, science education, critical thinking, primary literature

Author Info: Alexander J. Carroll, MSLS, AHIP, alex.carroll@ vanderbilt.edu, Librarian for STEM Research, Vanderbilt University, 419 21st Ave S, Nashville, TN 37212 


\section{PROBLEM CONTEXT}

After meeting their liaison librarian at a new student orientation event or during a curriculumintegrated guest lecture, early-career graduate students often schedule appointments to meet individually with their librarian. While students request these appointments ostensibly for help finding literature, many students end up expressing frustration about trying to make sense of the literature they have already found. While academic reading may seem like a fundamental skill that ought to be developed and refined during students' undergraduate careers, many graduate students nevertheless find their early encounters with primary literature in their field to be "bewildering and humbling," as they are asked to interpret documents with "highly technical language that is quite different from what they have experienced in textbooks and popular reviews." "That this scenario repeats itself across many academic and medical libraries suggests a need to examine the assumption that students enter graduate programs with a mastery of how to read technical literature effectively.

\section{WHY IS READING PRIMARY LITERATURE CHALLENGING FOR LEARNERS?}

Many learners, even graduate students entering highly selective programs in science or medicine, find the process of reading primary literature difficult. This should not surprise educators critically reading primary literature is a cognitively intensive process that is inherently taxing on the brain. ${ }^{2}$ Cognitively intensive processes require simultaneous use of working memory (things that are important to you in the present moment) and long-term memory (where ideas are retained to create meaning), ${ }^{3,4}$ When too many items are placed into a student's working memory at once, they experience cognitive overload, ${ }^{5}$ which negatively affects attention, information processing, and recall. ${ }^{6}$ To improve at cognitively complex tasks like reading primary literature, students need to engage in highly structured learning experiences. ${ }^{7}$ As such, for students to enter 
graduate programs prepared to engage with primary literature successfully, undergraduate programs must feature structured learning experiences on how to read primary literature that include guided practice and opportunities for feedback on performance.

This column challenges the assumption that students enter graduate school prepared to engage with primary literature by considering how science is taught to undergraduates, and will suggest that many undergraduate science, technology, engineering, and math (STEM) curricula do not provide students with the mastery of the science process skills needed to succeed in graduate and professional programs. Some possible reasons why this problem has remained so pervasive and persistent within graduate and professional educational programs follow, with reflections on potential implications this skill gap may have on equity, diversity, and inclusion efforts within science and medicine. The column will close by asserting that academic and medical librarians are well-equipped to help students in this area, providing a list of suggested skills that librarians can teach students to improve their ability to parse technical information effectively and efficiently.

\section{HOW IS STEM TAUGHT TO UNDERGRADUATES?}

At a fundamental level, undergraduate STEM curricula aim to train students how to think like scientists by teaching the processes of science. ${ }^{8}$ While specific content mastery varies by discipline, the core science process skills are broadly similar: developing hypotheses, visualizing and analyzing data, finding and interpreting primary literature, working collaboratively with peers, engaging in critical thinking to solve problems, and communicating results using multiple mediums. Collectively, these concepts help form the basis of the scientific method, the predominant epistemology of contemporary science and medicine. ${ }^{9,10}$ Faculty instructors have confirmed the value of these skills, ranking skills such as problem solving, interpreting data, and 
conducting an effective literature search among the most important skills students can gain during their undergraduate careers. ${ }^{11}$

Yet even while acknowledging the centrality of these skills, science educators rarely offer intentional instruction to undergraduates aimed at developing science process skills. Two common reasons identified for this disconnect are related issues: the "need to cover adequate content" and "teaching skills is too time consuming." 11 This choice to prioritize content over process comes with real costs, as demonstrated by the substantial evidence in science education literature on the benefits of process-oriented instruction. ${ }^{12}$ The evidence on the value of reading primary literature is especially compelling, with studies showing a link between facility with primary literature and critical thinking skills. ${ }^{13,14}$ Additionally, undergraduate training that emphasizes engagement with primary literature better prepares STEM undergraduates to matriculate into doctoral programs, ${ }^{15}$ and these benefits are particularly pronounced for historically underrepresented minorities pursuing STEM degrees. ${ }^{16}$ Without STEM educators placing an intentional emphasis on mastery of science process skills, students cannot be expected to enter graduate programs with these skills in hand.

\section{WHY HAS THIS PROBLEM PERSISTED?}

While science process skills are viewed as important knowledge for students, the prevailing mentality among many science educators was captured by the Congressional testimony of theninterim president of the National Academy of Engineering William Wulf, who asserted that "undergraduate education is about learning facts and graduate education is about learning the

process... by which those facts are discovered and validated." ${ }^{17}$ However, graduate students who do not engage deeply with primary literature as undergraduates matriculate into graduate programs at a distinct disadvantage. Not only will these students arrive without core skills 
needed to become successful scientists and clinicians, but three structural challenges will inhibit their ability to learn these skills quickly within their programs: 1) as content experts, faculty often have unfounded assumptions about their novice students; 2) students overrate their own science process skills; and 3) the culture of graduate school inhibits help-seeking behaviors.

\section{As Content Experts, Faculty Often Have Unfounded Assumptions}

\section{About Their Novice Students}

One of the obvious differences between faculty and graduate students is knowledge: simply put, faculty possess more relevant, contextualized knowledge about their domain area than do their

students. ${ }^{18}$ While often discussed in quantitative terms (e.g., an associate professor has spent X more years studying this topic than a graduate student), faculty also use categorically different approaches to cognitively intensive tasks, such as reading primary literature, than do their novice students. ${ }^{19}$ Experts, able to tap into their long-term memory, can use contextual knowledge when engaging with primary literature more easily than novices. Conversely, when faced with dense, context-rich objects like primary literature, graduate students often experience cognitive overload, which inhibits meaningful learning from occurring. ${ }^{6}$ Crucially, experts often do not recognize this difference, as they have forgotten how to think like novices. This phenomenon, often called the "expert blind spot," can render content experts ill-equipped pedagogically to teach novices, as their advanced knowledge interferes with their ability to understand the cognitive processes of their novice students. ${ }^{20}$

As a result, faculty often make false assumptions about their students, such as that students already know how to read academic writing. Or, as with information literacy skills, faculty may believe that academic reading is the sort of science process skill that is best learned 
by students engaging in self-directed learning, ${ }^{21}$ in which their internal motivation leads them to figure out these skills on their own. ${ }^{22,23}$ After all, these kinds of ad hoc, autodidactic approaches are how many faculty remember learning how to read the literature:

"I have no recollection of being taught to read a literature. I just sort of DID that as a graduate student. I was in the kind of lab where you were expected to really develop your own ideas almost from whole cloth, rather than fitting into an existing program of work." 24

However, research suggests that this kind of self-directed learning is less effective for novices, who require guided practice and feedback in order to realize skill gains in cognitively complex tasks. ${ }^{25}$ Moreover, this understanding of how graduate students ought to learn reflects survivor bias ${ }^{26}$ - only graduate students who managed to thrive in this sink-or-swim environment will matriculate into faculty positions, who will then in turn train their graduate students in this same manner. ${ }^{27}$ This phenomenon creates a feedback loop, which likely reinforces the systemic biases endemic to higher education, and which perpetuates the lack of diversity within science, technology, engineering, math, and medicine programs. ${ }^{28}$

\section{Students Overrate Their Own Science Process Skills}

Faculty may expect their intrinsically motivated graduate students to learn science process skills on their own, but reasons exist for further skepticism of the efficacy of this learning model. When asked to perform a self-assessment of their science process skills in tasks like literature searching, students often demonstrate overconfidence, overrating their own efficacy and abilities. ${ }^{29}$ In their study comparing student self-confidence and task mastery for information literacy, Molteni and Chan found that students who reported higher levels of self-confidence 
answered questions incorrectly as often as students who reported lower levels of self-confidence, but also were less likely to select "Not Sure." ${ }^{30}$ This suggests that one potential impact of overconfidence is that it creates barriers against acknowledging the limits of one's own understanding and of recognizing the complexity of highly challenging tasks. ${ }^{31}$ Unfortunately, this creates another negative feedback loop: As students' self-perceptions of their information literacy skills increases, their assessment of the value of information literacy instruction decreases. The resulting implication is that the prescribed solution of student's engaging in selfdirected learning is unlikely to be successful, as students will not be motivated to seek out additional training in science process skills on their own.

\section{The Culture of Graduate School Inhibits Help-seeking Behaviors}

In addition to many students overrating their skills in these areas upon entering graduate school, even those students who do engage in self-monitoring and who recognize the limits of their own understanding may be stymied by the culture of graduate school and health sciences residency programs. ${ }^{32}$ The culture of these highly selective academic programs often discourages students from engaging in help-seeking behaviors, since they fear that asking for help will be perceived as a sign of weakness or lack of preparedness. ${ }^{33}$ These barriers are more pronounced for women and historically underrepresented minorities in STEM programs, who may feel especially stigmatized when asking for help. ${ }^{34,35}$ When help-seeking behaviors become associated with a lack of content mastery, this creates yet another negative feedback loop, in which the students most in need of help become the least likely to seek out assistance. ${ }^{36}$

Taken together, these three barriers create significant impediments against students developing the science process skills they need to succeed in their graduate programs. While some of these skills may be more obviously applicable to the workflows of basic scientists, 
science process skills like literature searching and interpreting primary literature are equally important for students entering professional programs in the health sciences, as overconfidence in these areas may have downstream negative impacts on patient care. ${ }^{30}$ Given these stakes, academic and medical librarians should consider how they might contribute to efforts to overcome these barriers.

\section{WHY SHOULD LIBRARIANS ADDRESS PRIMARY LITERATURE LITERACY?}

If developing expertise in science process skills is a core aspect of becoming a scientist or clinician, then academic and medical librarians interested in promoting the success of their students should consider how they can help students learn to read and process information like scientists. Some science process skills, including evidence-based practice and information literacy, have become well-established components of graduate programs, ${ }^{37}$ with educators increasingly recognizing the value of integrating these topics into curricula strategically rather than through standalone workshops or orientations. ${ }^{38}$ At many institutions, librarians have become part of the teaching teams tasked with developing these programs. ${ }^{39}$ While these librarian-led training programs often focus on information retrieval, ${ }^{40}$ librarians frequently report a desire to provide students with training in other science process skills topics, such as critical appraisal and data literacy. ${ }^{41}$ Consequently, librarians are well-positioned to advocate for expanding existing evidence-based practice programs to include additional science process skills. ${ }^{42,43}$ Among these skills, primary literature literacy is a prime candidate for inclusion, as it represents one of the most exigent gaps in many early-career graduate students' science process skills.

Many academic and medical librarians may feel ill-equipped or inadequately trained to help students learn to interpret primary literature, ${ }^{44}$ which is often viewed as the domain of 
disciplinary faculty. ${ }^{45,46}$ Yet information professionals working in other settings would find this reticence surprising. Research has shown that public libraries can have a profound impact on the development of literacy skills in children, ${ }^{47}$ and school librarians serve as leaders in promoting literacy, reading comprehension, and fostering a passion for reading among students at every stage of primary and secondary education. ${ }^{48,49}$ But at the post-secondary level, librarians' area of expertise seemingly becomes much more limited in scope; academic librarians often focus primarily on information seeking and information retrieval, ${ }^{50}$ at most helping students to reflect on source selection criteria, such as relevance and authority. ${ }^{51}$ Even criticisms of this model largely interpret information literacy through the lenses of information seeking and retrieval. ${ }^{52}$ While some academic librarians have advocated for taking on the readers' advisory role so popular among public libraries ${ }^{53}$ these programs have largely been limited to building popular reading collections rather than developing literacy skills with primary literature. ${ }^{54}$

Several factors may prevent librarians from stepping into this instructional role comfortably; previous studies have found that medical librarians feel their lack of clinical knowledge and research design expertise make them ill-equipped to teach science process skills to clinicians. ${ }^{55}$ Yet this lack of domain expertise ironically positions librarians to step into a facilitative role that may lead to more meaningful student learning than didactic instruction. ${ }^{56}$ When asked for help with interpreting a piece of primary literature, a librarian may have easier access to the "novice mind" than might a disciplinary expert, ${ }^{57}$ and as a result can provide relevant strategies for early-career graduate students on how to best engage with the dense morass of technical information found in primary literature. When combined with an information professional's core skill sets and knowledge (e.g., an understanding of the structure of technical information, the impact of historical mediums on contemporary formats, the limitations of those 
traditional structures, etc.), librarians are in fact very well-equipped to take on this role. Crucially, librarians also exist outside the hierarchical lines of authority and often fraught powerdynamics that graduate students must navigate, making a librarian's office a safer place for students to ask what they may perceive as vulnerable questions. ${ }^{58}$

\section{WHAT SPECIFIC PRIMARY LITERATURE LITERACY SKILLS}

\section{CAN LIBRARIANS TEACH STUDENTS?}

Over several decades, science educators have developed several effective strategies for helping students to read primary literature..$^{59,60,61}$ These strategies are neither novel nor experimental; rather, they are grounded in the best available evidence of how students learn. ${ }^{62,63}$ Table 1 provides summaries of several of the most widely adopted strategies and techniques.

\section{[INSERT TABLE 1 HERE]}

\section{Table 1: Active reading strategies to model for students}

Crucially, educators have found that these approaches work even in jargon-intensive disciplines that can appear ostensibly inscrutable to the uninitiated. ${ }^{64}$ When using these strategies, students repeatedly have shown the ability not only to understand the fundamental concepts expressed in primary literature, but also to propose new research questions based on the findings and limitations of a given study. Librarians interested in sharing these strategies with students should consider modeling these behaviors to students during a curriculum-integrated guest lecture or a reference consultation just as they would model effective information seeking behaviors within a database.

CONCLUSIONS 
Promoting literacy and facility with technical information falls squarely within any definition of librarianship. For librarians interested in expanding their teaching portfolios beyond one-shot classes or workshops on database searching, ${ }^{65}$ facilitating learning experiences on how to read primary literature represents an opportunity to address a critical, clear need for students. While all students stand to benefit from additional training in this area, these benefits likely will be most pronounced for students from historically underrepresented minorities, suggesting that intentional efforts by librarians in this area may also advance institutional equity, diversity, and inclusion. Dedicating time to model active reading techniques may come with tradeoffs - for example, librarians may find that by discussing how to read literature, they have less time to model advanced information retrieval skills. However, providing instruction in this science process skill will reinforce the recognition that librarians have valuable expertise that can help students learn many of the skills they need to "think like a scientist," making it more likely that students will return to a librarian with future information and data adjacent problems.

\section{ACKNOWLEDGEMENTS}

The author acknowledges Dr. Alison R. Carroll, Pediatric Hospital Medicine Fellow at Vanderbilt University Medical Center, and Mr. Kevin Michael Klipfel, Instructional Design and Assessment Librarian at the University of Southern California, for serving as internal reviewers of an earlier version of this column. 
Table 1: Active reading strategies to model for learners

\begin{tabular}{|l|l|}
\hline Active reading strategies & Example practices \\
\hline $\begin{array}{l}\text { Understanding the structure of an article: } \\
\text { the sections of primary literature serve } \\
\text { distinct and unique rhetorical functions. }\end{array}$ & $\begin{array}{l}\text { Explaining what "answers" a reader can expect to } \\
\text { find in each section. Offering suggestions on } \\
\text { which sections to read first. }\end{array}$ \\
\hline $\begin{array}{l}\text { Reading "out of order": primary } \\
\text { literature should not be read front-to-back } \\
\text { like a novel. }\end{array}$ & $\begin{array}{l}\text { Examining tables and figures before reading } \\
\text { prose. Reading topic sentences to survey the } \\
\text { prose before reading full paragraphs. }\end{array}$ \\
\hline $\begin{array}{l}\text { Critical note taking: creating meaningful } \\
\text { notes requires more than highlighting } \\
\text { relevant sections. }\end{array}$ & $\begin{array}{l}\text { Restating main takeaways in their own words. } \\
\text { Writing questions that highlight gaps in their own } \\
\text { current understanding. Underlining words and } \\
\text { phrases they do not understand. }\end{array}$ \\
\hline $\begin{array}{l}\text { Reading in parallel: reading multiple } \\
\text { things "at once" promotes transfer and } \\
\text { meaning making. }\end{array}$ & $\begin{array}{l}\text { Reviewing previously read articles for connection } \\
\text { points. Utilizing secondary literature as a } \\
\text { supplement. }\end{array}$ \\
\hline $\begin{array}{l}\text { Reading in teams: discussing an article } \\
\text { with a classmate or colleague can } \\
\text { facilitate peer learning. }\end{array}$ & $\begin{array}{l}\text { Comparing notes and unfamiliar concepts with } \\
\text { another learner studying the same topic. Sharing } \\
\text { relevant secondary literature sources that can } \\
\text { provide definitions for technical jargon. }\end{array}$ \\
\hline
\end{tabular}




\section{REFERENCES}

1. Janick-Buckner, Diane. "Getting Undergraduates to Critically Read and Discuss Primary Literature." Journal of College Science Teaching 27, no. 1 (September/October 1997: 29-33.

2. Willingham, Daniel T. Why Don't Students Like School?: A Cognitive Scientist Answers Questions about How the Mind Works and What It Means for the Classroom. San Francisco, CA: Jossey-Bass, 2009.

3. Baddeley, Alan. "Working Memory: Looking Back and Looking Forward," Nature Reviews Neuroscience 4, no. 10 (October 2003): 829-39. https://doi.org/10.1038/nrn1201.

4. Burmester, Alex. "Working Memory: How You Keep Things 'in Mind' over the Short Term," The Conversation. (June 4, 2017). http://theconversation.com/working-memory-howyou-keep-things-in-mind-over-the-short-term-75960.

5. Cowan, Nelson, Candice C. Morey, Angela M. AuBuchon, et al. "Seven-Year-Olds Allocate Attention like Adults Unless Working Memory Is Overloaded.” Developmental Science 13, no. 1 (January 1, 2010): 120-33. https://doi.org/10.1111/j.1467-7687.2009.00864.x.

6. Sweller, John. “Cognitive Load During Problem Solving: Effects on Learning,” Cognitive Science 12, no. 2 (April 1, 1988): 257-85. https://doi.org/10.1207/s15516709cog1202_4.

7. Ericsson, K Anders, Ralf T. Krampe, and Clemens Tesch-Römer. “The Role of Deliberate Practice in the Acquisition of Expert Performance.” Psychological Review 100, no. 3 (July 1993): 363-709.

8. Handelsman, Jo, Diane Ebert-May, Robert Beichner, et al. "Scientific Teaching." Science 304, no. 5670 (April 23, 2004): 521-22. https://doi.org/10.1126/science.1096022. 
9. Gauch Jr., Hugh G. Scientific Method in Practice (Cambridge University Press, 2003);

10. Hanne Andersen and Brian Hepburn, "Scientific Method," in The Stanford Encyclopedia of Philosophy, ed. Edward N. Zalta, Summer 2016 (Metaphysics Research Lab, Stanford University, 2016). https://plato.stanford.edu/archives/sum2016/entries/scientific-method/.

11. Coil, David, Mary Pat Wenderoth, Matthew Cunningham, et al. "Teaching the Process of Science: Faculty Perceptions and an Effective Methodology." CBE—Life Sciences Education 9, no. 4 (December 1, 2010): 524-35. https://doi.org/10.1187/cbe.10-01-0005.

12. Gormally, Cara, Peggy Brickman, Brittan Hallar, et al. "Effects of Inquiry-Based Learning on Students' Science Literacy Skills and Confidence." International Journal for the Scholarship of Teaching and Learning 3, no. 2 (July 2009). https://doi.org/10.20429/ijsotl.2009.030216

13. Hoskins, Sally G., Leslie M. Stevens, Ross H. Nehm. "Selective Use of the Primary Literature Transforms the Classroom into a Virtual Laboratory." Genetics 176, no. 3 (July 1, 2007): 1381-89. https://doi.org/10.1534/genetics.107.071183.

14. Gehring, Kathleen M., Deborah A. Eastman. "Information Fluency for Undergraduate Biology Majors: Applications of Inquiry-Based Learning in a Developmental Biology Course." CBE—Life Sciences Education 7, no. 1 (March 1, 2008): 54-6., https://doi.org/10.1187/cbe.0710-0091.

15. Kozeracki, Carol A.,Michael F. Carey, John Colicelli, et al. “An Intensive PrimaryLiterature-Based Teaching Program Directly Benefits Undergraduate Science Majors and Facilitates Their Transition to Doctoral Programs." CBE—Life Sciences Education 5, no. 4 (December 1, 2006): 340-47. https://doi.org/10.1187/cbe.06-02-0144. 
16. Dirks, Clarissa, and Matthew Cunningham. "Enhancing Diversity in Science: Is Teaching Science Process Skills the Answer?.” CBE_Life Sciences Education 5, no. 3 (September 1, 2006): 218-26. https://doi.org/10.1187/cbe.05-10-0121.

17. United States Congress. "Technology and the Virtual University: Opportunities and Challenges." Senate Committee on Labor and Human Resources on Reauthorization of the Higher Education (1997).

18. Ericsson, K. Anders., and Jacqui Smith, eds. Toward a General Theory of Expertise: Prospects and Limits. Carlsbad, CA: Cambridge University Press (1991).

19. Ericsson, K. Anders. "Protocol Analysis and Expert Thought: Concurrent Verbalizations of Thinking during Experts' Performance on Representative Tasks," in The Cambridge Handbook of Expertise and Expert Performance, ed. K. Anders Ericsson et al. Cambridge: Cambridge University Press (2006): 223-42. https://doi.org/10.1017/CBO9780511816796.013.

20. Nathan, Mitchell J, Kenneth R. Koedinger, and Martha W Alibali. "Expert Blind Spot: When Content Knowledge Eclipses Pedagogical Content Knowledge.'In Proceedings of the Third International Conference on Cognitive Science. Beijing, China: USTC Press, 2001): 644-48.

21. Leckie, Gloria J., and Anne Fullerton. "Information Literacy in Science and Engineering Undergraduate Education: Faculty Attitudes and Pedagogical Practices." College \& Research Libraries 60, no. 1 (January 1, 1999): 9-29. https://doi.org/10.5860/crl.60.1.9.

22. Saunders, Laura. "Faculty Perspectives on Information Literacy as a Student Learning Outcome.” The Journal of Academic Librarianship 38, no. 4 (July 1, 2012): 226-36. https://doi.org/10.1016/j.acalib.2012.06.001. 
23. Kirschner, Paul A., and Jeroen J.G. van Merriënboer. "Do Learners Really Know Best? Urban Legends in Education.” Educational Psychologist 48, no. 3 (July 2013): 169-83. https://doi.org/10.1080/00461520.2013.804395.

24. "Reading the Literature and Writing." Drugmonkey (blog). (April 20, 2020). https://drugmonkey.scientopia.org/2020/04/20/reading-the-literature-and-writing/.

25. Feltovich, Paul J., Michael A. Prietula, and K. Anders Ericsson. "Studies of Expertise from Psychological Perspectives." In The Cambridge Handbook of Expertise and Expert Performance. New York, NY, US: Cambridge University Press, (2006): 41-67. https://doi.org/10.1017/CBO9780511816796.004.

26. Shermer, Michael. "Surviving Statistics." Scientific American 311, no. 3 (August 19, 2014): 94-94. https://doi.org/10.1038/scientificamerican0914-94.

27. Fischer, Elisabeth, and Martin Hänze. "How Do University Teachers' Values and Beliefs Affect Their Teaching?" Educational Psychology 40, no. 3 (March 15, 2020): 296-317. https://doi.org/10.1080/01443410.2019.1675867.

28. Whittaker, Joseph A., and Beronda L. Montgomery. "Cultivating Diversity and Competency in STEM: Challenges and Remedies for Removing Virtual Barriers to Constructing Diverse Higher Education Communities of Success." Journal of Undergraduate Neuroscience Education 11, no. 1 (October 15, 2012): A44-51.

29. Mahmood, Khalid. "Do People Overestimate Their Information Literacy Skills? A Systematic Review of Empirical Evidence on the Dunning-Kruger Effect." Communications in Information Literacy 10, no. 2 (December 29, 2016). https://doi.org/10.15760/comminfolit.2016.10.2.24. 
30. Molteni, Valeria E., and Emily K. Chan, "Student Confidence/Overconfidence in the Research Process.” The Journal of Academic Librarianship 41, no. 1 (January 1, 2015): 2-8. https://doi.org/10.1016/j.acalib.2014.11.012.

31. Kruger, Justin, and David Dunning. "Unskilled and Unaware of It: How Difficulties in Recognizing One's Own Incompetence Lead to Inflated Self-Assessments.” Journal of Personality and Social Psychology 77, no. 6 (December 1999): 1121-34.

32. Kennedy, Tara J. T., Glenn Regehr, G. Ross Baker, et al. "'It's a Cultural Expectation...' The Pressure on Medical Trainees to Work Independently in Clinical Practice." Medical Education 43, no. 7 (2009): 645-53. https://doi.org/10.1111/j.1365-2923.2009.03382.x.

33. Payakachat, Nalin, Paul O. Gubbins, Denise Ragland, et al. “Academic Help-Seeking Behavior Among Student Pharmacists.” American Journal of Pharmaceutical Education 77, no. 1 (February 12, 2013). https://doi.org/10.5688/ajpe7717.

34. Vogt, Christina M., Dennis Hocevar, and Linda Serra Hagedorn. “A Social Cognitive Construct Validation: Determining Women's and Men's Success in Engineering Programs.” The Journal of Higher Education 78, no. 3 (2007): 337-64.;

35. Inda, Mercedes, Carmen Rodríguez, and José Vicente Peña. “Gender Differences in Applying Social Cognitive Career Theory in Engineering Students," Journal of Vocational Behavior 83, no. 3 (December 1, 2013): 346-55. https://doi.org/10.1016/j.jvb.2013.06.010.

36. Herring, Christopher and Joachim Walther. "Academic Help-Seeking as a Stand-Alone, Metacognitive Action: An Empirical Study of Experiences and Behaviors in Undergraduate Engineering Students.” In 2016 ASEE Annual Conference \& Exposition Proceedings (2016 
ASEE Annual Conference \& Exposition, New Orleans, Louisiana: ASEE Conferences, 2016), 26490. https://doi.org/10.18260/p.26490.

37. Blanco, Maria A., Carol F. Capello, Josephine L. Dorsch, et al. "A Survey Study of Evidence-Based Medicine Training in US and Canadian Medical Schools.” Journal of the Medical Library Association 102, no. 3 (July 2014): 160-68. https://doi.org/10.3163/15365050.102.3.005.

38. Wallace, Margaret C., Allison Shorten, Patrick Crookes. "Integrating Information Literacies into an Undergraduate Nursing Programme." Nurse Education Today 19, no. 2 (February 1, 1999): 136-41. https://doi.org/10.1054/nedt.1999.0621.

39. Klem, Mary L, and Patricia M. Weiss. "Evidence-Based Resources and the Role of Librarians in Developing Evidence-Based Practice Curricula." Journal of Professional Nursing 21, no. 6 (November 1, 2005): 380-87. https://doi.org/10.1016/j.profnurs.2005.10.004.

40. Maggio, Lauren A., and Janice Y. Kung. "How Are Medical Students Trained to Locate Biomedical Information to Practice Evidence-Based Medicine? A Review of the 2007-2012 Literature.," Journal of the Medical Library Association 102, no. 3 (July 2014): 184-91. https://doi.org/10.3163/1536-5050.102.3.008.

41. Maden-Jenkins, Michelle. "Healthcare Librarians and the Delivery of Critical Appraisal Training: Attitudes, Level of Involvement and Support." Health Information \& Libraries Journal 27, no. 4. (May 12, 2011): 304-15. https://doi.org/10.1111/j.1471-

1842.2010.00899.x@10.1111/(ISSN)1471-1842.meeting-the-challenges-of-clinical-informationprovision. 
42. Federer, Lisa M., Ya-Ling Lu, and Douglas J. Joubert. "Data Literacy Training Needs of Biomedical Researchers." Journal of the Medical Library Association 104, no. 1 (January 2016): 52-57. https://doi.org/10.3163/1536-5050.104.1.008.

43. Thielen, Joanna, and Amanda Nichols Hess. "Advancing Research Data Management in the Social Sciences: Implementing Instruction for Education Graduate Students into a Doctoral Curriculum." Behavioral \& Social Sciences Librarian 36, no. 1 (January 2, 2017): 16-30. https://doi.org/10.1080/01639269.2017.1387739.

44. Maden-Jenkins, Michelle. "Healthcare Librarians and the Delivery of Critical Appraisal Training: Barriers to Involvement," Health Information \& Libraries Journal 28, no. 1 (March 2011): 33-40, https://doi.org/10.1111/j.1471-1842.2010.00922.x.

45. Clark, Melanie, Kimberly Vardeman, and Shelley Barba. "Perceived Inadequacy: A Study of the Imposter Phenomenon among College and Research Librarians." College \& Research Libraries 75, no. 3 (May 2014): 255-71. https://doi.org/10.5860/crl12-423.

46. Parkman, Anna. "The Imposter Phenomenon in Higher Education: Incidence and Impact." Journal of Higher Education Theory and Practice 16, no. 1 (2016). https://doi.org/10.33423/jhetp.v16i1.1936.

47. Celano, Donna, and Susan B. Neuman. "The Role of Public Libraries in Children's Literacy Development an Evaluation Report." Harrisburg, PA: Pennsylvania Library Association (February 2001).

48. Smalley, Topsy N. "College Success: High School Librarians Make the Difference." The Journal of Academic Librarianship 30, no. 3 (May 1, 2004): 193-98, https://doi.org/10.1016/j.acalib.2004.02.008. 
49. Achterman, Douglas L. "Haves, Halves, and Have-Nots: School Libraries and Student Achievement in California.” Denton, TX, University of North Texas (2008). https://digital.library.unt.edu/ark:/67531/metadc9800/m2/1/high_res_d/dissertation.pdf.

50. Association of College \& Research Libraries. "Information Literacy Competency Standards for Higher Education.” (January 18, 2000).

http://www.ala.org/acrl/standards/informationliteracycompetency.

51. Blakeslee, Sarah. "The CRAAP Test.” LOEX Quarterly 31, no. 3 (2004).

https://commons.emich.edu/loexquarterly/vol31/iss3/4/.

52. Association of College \& Research Libraries, "Framework for Information Literacy for Higher Education,” January 16, 2015, http://acrl.ala.org/ilstandards/wpcontent/uploads/2015/01/Framework-MW15-Board-Docs.pdf.

53. Smith, Rochelle and Nancy J. Young, "Giving Pleasure Its Due: Collection Promotion and Readers' Advisory in Academic Libraries," The Journal of Academic Librarianship 34, no. 6 (November 1, 2008): 520-26, https://doi.org/10.1016/j.acalib.2008.09.003.

54. Dewan, Pauline. "Why Your Academic Library Needs a Popular Reading Collection Now More Than Ever," College \& Undergraduate Libraries 17, no. 1 (March 3, 2010): 44-64, https://doi.org/10.1080/10691310903584775.

55. Booth, Andrew and Anne Brice, "Column Editors," Health Information \& Libraries Journal 18, no. 3 (2001): 175-77, https://doi.org/10.1046/j.1471-1842.2001.00340.x-i2.

56. King, Alison. "From Sage on the Stage to Guide on the Side," College Teaching 41, no. 1 (January 1, 1993): 30-35, https://doi.org/10.1080/87567555.1993.9926781. 
57. Ross, Philip E. "The Expert Mind," Scientific American 295, no. 2 (2006): 64-71.

58. Carroll, Alexander J., Honora N. Eskridge, and Bertha P. Chang, "Lab-Integrated Librarians: A Model for Research Engagement," College \& Research Libraries 81, no. 1 (January 2020): 826, https://doi.org/10.5860/crl.81.1.8.

59. Epstein, Herman T. “An Experiment in Education,” Nature 235 (1972): 203-5;

60. Goddard, Nancy and Mary Sue Henifin, "A Feminist Approach to the Biology of Women," Women's Studies Quarterly 12, no. 4 (1984): 11-18;

61. McNeal, Ann P. "Real Science in the Introductory Course," New Directions for Teaching and Learning 1989, no. 38 (1989): 17-24, https://doi.org/10.1002/t1.37219893804.

62. Klipfel, Kevin M. and Dani B. Cook, Learner-Centered Pedagogy: Principles and Practice (Chicago: American Library Association, 2017);

63. Carroll, Alexander J. and Kevin M. Klipfel, "Talent, Schmalent: An Instructional Design/Action Research Framework for the Professionalization of Teaching in Academic Libraries," The Journal of Academic Librarianship 45, no. 2 (2019): 110-18, https://doi.org/10.1016/j.acalib.2019.01.009.

64. Herman, Carolyn, "Reading the Literature in the Jargon-Intensive Field of Molecular Genetics: Making Molecular Genetics Accessible to Undergraduates Using a Process-Centered Curriculum," Journal of College Science Teaching 28, no. 4 (1999): 252-53.

65. Kvenild, Cassandra and Kaijsa Calkins, Embedded Librarians: Moving Beyond One-Shot Instruction (Chicago: American Library Association, 2011). 